\title{
Insolating Passive Heating Systems of Premises with Three-Layer Energy Active Translucent Enclosure and Short-Term Heat Accumulator
}

\author{
Rabbonokul Rakhmanovich Avezov², Nilufar Rabbanakulovna Avezova ${ }^{1,2}$, Ergashali \\ Yuldashevich Rakhimov ${ }^{2}$, Muradbek Artikaliyevich Kuralov ${ }^{1,2}$ \\ ${ }^{1}$ International Solar Energy Institute, Tashkent, Uzbekistan \\ ${ }^{2}$ Physical-Technical Institute SPA “Physics-Sun” of Academy Sciences of Republic of Uzbekistan
}

Tashkent, Uzbekistan

\begin{abstract}
In this article is proposed the insolation passive heating system of premises with an energy-active three-layer translucent enclosure and short-term phase-change heat accumulators, enabling to increase their efficiency to 5$10 \%$, as well as the results of calculation studies on determining of the heat capacity of short-term phase-change heat accumulators.

Keywords: solar energy; energy active translucent enclosures; phase-change heat storing materials; phasechange heat accumulator.

The Indices Upper:

te $\quad:$ Translucent enclosure

The Indices Lower:

use :Useful

$\mathrm{p} \quad$ :Surface light-absorbing heat-exchange panel

hl :Heat looses

te :Translucent enclosure

fall :Falling

acc :Accumulator
\end{abstract}

\section{INTRODUCTION}

In world practice, research in the field of solar energy for heating of buildings and derived mainly carried out in the direction of the development and implementation of passive solar heating systems that are different from active systems primarily easy of constructive solutions. Among the passive solar heating systems in temperate regions, most widely insolation systems based on the direct entry of solar radiation energy in the heated premises through their double-layer light transparent enclosures with larger dimensions (compared to normal) on the south wall.

The advantages of this type of heating systems is their simplicity, their lack of special heliotechnical equipment, pumps and fans to pump coolant through the system and, consequently, their high thermal efficiency, low cost and low operating costs. The disadvantages of these systems is the potential light and heat discomfort difficulty regulating temperature environment air heated space. This factor explains the unpopularity of the considered solar heating systems in terms of regions with sharply continental climate, to which a large part of the territory of our republic belongs. To scale up insolating heating systems in practice, heating of residential and administrative buildings in the first place it is necessary to eliminate these shortcomings, while retaining all of the above those of their benefits.

\section{PROPOSAL TECHNICAL SOLUTION}

One solution to this problem proposed by Uzbek scientists working in the field of solar energy, is the replacement of the simple two-layer translucent enclosures from ordinary window glass on the threelayer energy active translucent enclosure, an inner layer which is on the outside covered with a thin part light absorbing laminate film polymeric materials . 
Rabbonokul Rakhmanovich Avezov et al. "Insolating Passive Heating Systems of Premises with ThreeLayer Energy Active Translucent Enclosure and Short-Term Heat Accumulator”

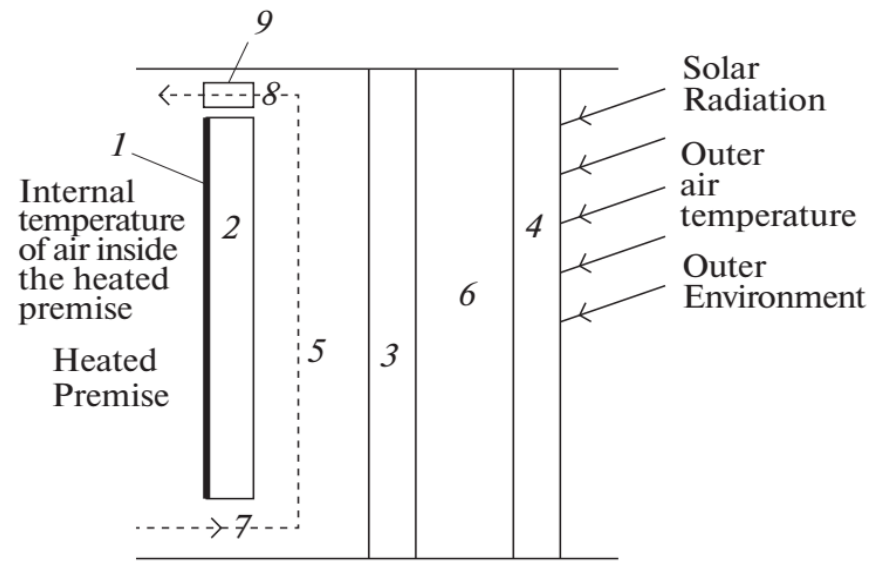

Figure1. Basic scheme and operating principle of the three-layer energy-efficient translucent enclosure of passive solar heating systems: (1) thin partially absorbing polymeric film cover (laminate film); (2) internal layer of three-layer translucent enclosure; (3) medium layer of three-layer translucent enclosure; (4) external layer of three-layer translucent enclosure; (5) ventilated (the vent) air layer; (6) isolated air layer; (7) and (8) are circulation channels; (9) short-term (24-hour) phase-change heat accumulator.

The air gap between the inner and middle layers of translucent enclosures is made in the form of air holes (i.e. vented). The air gap between the middle and the outer layer is made of a closed.

As a result of conducted work on the definition of the annual variation the replacement coefficient of insolating passive heating systems with three-layer energy-active translucent enclosure monthly heating season, as well as thermal optimization of the surface area of the three-layer energy active translucent enclosure premises with insolating passive heating systems, set that the climatic conditions of the Republic of Uzbekistan according to calculations, as well as relevant experimental researches when the condition (ratio of translucent enclosure surface area to the floor space surface area [1]), during the daytime the environment air temperature premise is higher than of the normalized $(+18$ ${ }^{\circ} \mathrm{C}$ ), identified the need of accumulation daytime excess of heat. The possibility of accumulation of daily heat surplus occurs in the beginning (from October 15 to November 15) and the end (from 15 March to 15 April), the heating period.

The temperatures of the heating agent are usually low for passive solar heating systems, thus, in order to store the diurnal solar heat surplus, application of phase-change materials with melting temperatures of $\approx 20^{\circ} \mathrm{C}$ can be of interest; information about these materials is detailed in [2-5].

Phase-change heat storing materials are usually placed in small containers and flat trays to increase the area of their surfaces exchanging heat with air in the heated premise. Application of lowtemperature phase-change accumulators designed in the form of thin layers adjacent to internal surfaces of ceiling plates is recommended in premises with passive solar heating [2].

When low-temperature phase-change substances are used to store heat in passive solar heating systems, the expression for the specific weight of material in the accumulator (per unit of translucent enclosure surface area), can be written as follows [6]:

$m_{a c c}=\frac{\sum_{i}\left(\eta_{t e} q_{\text {fall }}^{t e} \Delta \tau\right)_{i}-\sum_{i}\left(q_{h l}^{h p} \Delta \tau\right)_{i}}{r_{a c c}+\left(c_{p} \Delta t\right)_{a c c}}$,

where $r_{\text {acc }}$ is the latent heat of phase transition of the heat-accumulating substance; $c_{p_{a c c}}$ and $\Delta t_{a c c}$ are the specific heat capacity and the diurnal change of temperatures of the phase-change heataccumulating substance in the liquid state. 
Rabbonokul Rakhmanovich Avezov et al. "Insolating Passive Heating Systems of Premises with ThreeLayer Energy Active Translucent Enclosure and Short-Term Heat Accumulator"

\section{NUMERICAL CALCULATIONS}

Here is an example of specific weight calculation for a short-term phase-change heat accumulator based on $\left(\mathrm{CH}_{3}\right)_{2} \mathrm{SO}$, whose melting point is $18.6^{\circ} \mathrm{C}$, latent heat of phase transition is $173 \mathrm{~kJ} / \mathrm{kg}$, specific heat capacity (in liquid state) is $1.97 \mathrm{~kJ} /\left(\mathrm{m}^{2} \cdot{ }^{\circ} \mathrm{C}\right.$ ), and density is $1100 \mathrm{~kg} / \mathrm{m}^{3}$ for the heated premise (conventional object) with specific thermal characteristic $1.2 \mathrm{~W} /\left(\mathrm{m}^{2} \cdot{ }^{\circ} \mathrm{C}\right)$, floor surface area 15 $\mathrm{m}^{2}$, volume $45 \mathrm{~m}^{3}$, and surface area of translucent enclosure $3.75 \mathrm{~m}^{2}$. Diurnal (during $8 \mathrm{~h}$ ) total solar flux (direct and diffuse) incident on the surface of translucent enclosure is $11000 \mathrm{~kJ} / \mathrm{m}^{2}$. Average diurnal thermal efficiency of the considered translucent enclosure is 0.6. Average diurnal outer air temperature is $+5^{\circ} \mathrm{C}$, and normalized air temperature in the heated premise is $+18^{\circ} \mathrm{C}$.

Then, the diurnal heat loss of the heated premise is calculated as follows:

$$
Q_{h l}^{h p}=1.2 \cdot 45 \cdot(18-5) \cdot 8 \cdot 3600=20217.6 \mathrm{~kJ},
$$

and the diurnal heat output of the translucent enclosure is:

$$
Q_{\text {use }}^{\text {te }}=0.6 \cdot 1100 \cdot 3.75=24750 \quad k J,
$$

The diurnal solar heat surplus in the heated premise to be accumulated is:

$$
Q_{u s e}^{t e}-Q_{h l}^{h p}=24750-20217 \quad .6=4532 \quad .4 k J .
$$

The mass of the phase-change heat accumulator of passive heating systems, if warm air temperature at the vent exit is $40^{\circ} \mathrm{C}$ and the temperature of the phase-change heat accumulator in the liquid state is $35^{\circ} \mathrm{C}$, for the considered object, can be found as follows:

$$
M_{a c c}=\frac{4532.4}{173+1.97 \cdot(35-20)}=22.4 \mathrm{~kg}
$$

Here, the specific weight of the heat accumulator is $m_{\text {acc }}=22.4 / 3.75=6 \mathrm{~kg} / \mathrm{m}^{2}$, which makes it possible to place it at the exit of the vent of the translucent enclosure, as shown in Figure 1.

\section{CONCLUSION}

The proposed insolating passive heating system of premise with an energy-active three-layer translucent enclosure and short-term heat accumulators, allows increasing the replacement factor of fossil fuel consuming for system needs up to $40-45 \%$.

\section{REFERENCES}

[1] R.R.Avezov, N.R.Avezova, M.A.Kuralov, D.U.Abdukhamidov, "Temperaturnyi rezhim vozdushnoi sredy pomesheni s insollatsionoi passivnoi sistemoi otopleniya," Zhurnal S.O.K. (Santekhnika Otoplenie Konditsionirovanie), №10. - pp. 39-40. 2015.

[2] J.A. Duffie, and W.A. Beckman, "Solar Engineering Thermal Processes," Wiley, 1980.

[3] T.E. Johnson, "Lightweight Thermal Storage for Solar Heated Buildings," Solar Energy, vol.19, No.6, pp. 669-675, 1977.

[4] A. Abhat, "Low Temperature Latent Heat Thermal Energy Storage: Heat Storage materials," Solar Energy, vol. 30, No. 4, pp. 313-312, 1983.

[5] C. Barreneche, M.E. Navarro, L.F. Gabera, A.I. Fernande, "New database to select phase change materials: Chemical nature, properties, and applications," Journal of Energy Storage, No.3, pp. 18-24, 2015.

[6] R. R. Avezov, D. U. Abdukhamidov, M. A. Kuralov, E. Yu. Rakhimov, "The evaluation of heat capacity and choice of materials for short-term storage of diurnal solar heat surplus in passive solar heating systems," Applied Solar Energy, vol. 52, No. 4, pp. 305-308, 2016. 
Rabbonokul Rakhmanovich Avezov et al. "Insolating Passive Heating Systems of Premises with ThreeLayer Energy Active Translucent Enclosure and Short-Term Heat Accumulator"

\section{AUTHOR'S BIOGRAPHY}

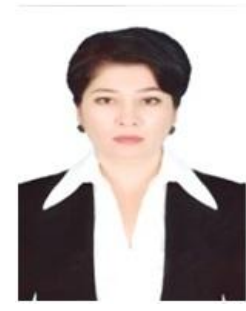

Nilufar Rabbanakulovna Avezova is a scientist in the field of solar power, the leading researcher and the head of the laboratory "Solar-thermal and power installations", also is the head of fundamental, scientific-technical and innovative projects at the Physical-Technical Institute of SPA "Physics-Sun" of Academy of Sciences of the Republic of Uzbekistan. In the same time at the International Solar Energy Institute the head of department "Solar heat supply". Executive secretary of the international scientific journal "Applied Solar Energy". 